\title{
Pendampingan Program Pemenuhan Kebutuhan Pangan Melalui Hidroponik Menggunakan Media Botol Bekas Di Kabupaten Tulungagung
}

\section{Mufida Diah Lestari dan Herry Nur Faisal}

\author{
Universitas Tulungagung \\ mufida@unita.ac.id, herrynurfaisal@unita.ac.id
}

\begin{abstract}
The empowerment of Community service to meet the food needs fulfillment by using hydroponics with the bottles as the media is intended to build the understanding of the community especially those who live in urban areas crops have the hydroponic method as well as providing home garden. This way can help them fulfill food needs households the expextation of this program is as a booster to foster community interest in consuming vegetables, able to fulfill daily needs, maximizing the fungtion of the yard and also become a pilot project for other regions to be able to develop suitable crops using holtikultural methods. This method is a cheaper and more efficient in cost.
\end{abstract}

\section{Keyword: hydroponic; farming; narrow land}

\begin{abstract}
Abstrak
Pengabdian kepada masyarakat dengan format pendapingan program pemenuhan kebutuhan pangan melalui hidroponik menggunakan media botol bekas di Kabupaten Tulungagung memiliki tujuan memberikan pemahaman kepada masyarakat khusunya yang tinggal di perkotaan bahwa mereka dapat bercocok tanam dengan menggunakan metode hidroponik serta memberikan pemanfaatan lahan pekarangan rumah sebagai upaya pemenuhan kebutuhan pangan rumah tangga dengan menggunakan botol bekas dan masih bisa dipakai. Harapan dari berjlanannya program ini adalah dapat menumbuhkan minat masyarakat untuk mengkonsumsi sayur, mampu memenuhi kebutuhan sehari-hari, memaksimalkan fungsi pekarangan dan juga menjadi pilot projeck bagi daerah lain untuk dapat mengembangkan cocok tanam dengan menggunakan metode hortikultura namun dengan biaya yang murah dan lebih efisien.
\end{abstract}

Kata Kunci: hydroponic; bercocok tanam; lahan sempit 


\section{A. PENDAHULUAN}

Dunia pertanian menduduki peran penting di masyarakat karena merupakan sumber pangan utama dan menjadikannya kebutuhan utama pemenuhan kebutuhan pangan masyarakat. Wilayah yang sangat mendukung, dengan kondisi tanah yang cukup baik serta letak geografis yang sangat strategis membuat sector pertanian menjadi salah satu sektor yang sangat berpengaruh.

Kebutuhan pangan menjadi faktor utama karena masyarakat dihadapkan pada kebutuhan pangan sehat dan kaya gizi. Namun, saat ini masyarakat karena keterbatasan lahan yang dimiliki khususnya daerah perkotaan menyebabkan masyarakat tidak dapat memenuhi kebutuhan pangan mereka. Masyarakat daerah perkotaan memiliki kecenderungan enggan untuk melakukan cocok tanam / bertani karena merasa mereka tidak memiliki waktu luang dan merasa bahwa mereka tidak cukup terampil dalam bercocok tanam. Usaha pemenuhan kebutuhan dari masyarakat perkotaan ini adalah dengan mengupayakan mengenai pemanfaatan pekarangan rumah menjadi lebih berfungsi melalui bercocok tanam dengan metode hidroponik.

Metode Hidroponik merupakan sebuah metode budidaya menanam dengan menggunakan air tanpa menggunakan tanah dengan menekankan pada pemenuhan kebutuhan nutrisi bagi tanaman. Hidroponik dapat dijadikan salah satu alternative dalam bercocok tanam tanpa memerlukan lahan yang luas dan lebih efisien. Hidroponik identik dengan modal yang cukup besar, namun dalam hal ini dapat dilakukan dengan meminimalisir modal yang digunakan untuk bercocok tanam dengan menggunakan botol bekas sebagai media. Hidroponik dengan menggunakan bootl bekas dirasa lebih efektif dan efisien, pada metode hidroponik menggunakan botol ini dapat dilakukan untuk menanam anek tumbuhan dan sayur-sayuran seperti kangkung, selada, dan sawit.

Karakteristik masyarakat perkotaan dengan lahan yang sempit namun ingin melakukan cocok tanam metode hidroponik ini menjadi alternative yang cukup baik. Untuk itu peneliti ingin melakukan pendampingan dengan masyarakat daerah perkotaan di Kabupaten Tulungagung sebagai usaha pemenuhan kebutuhan pangan skala rumah tangga.

\section{B. PELAKSANAAN DAN METODE}

Pelaksanaan kegiatan pengabdian masyarakat mengenai strategi pemenuhan kebutuhan pangan melalui hidroponik dengan media botol bekas di Kecamatan Tulungagung. Kegiatan ini menggunakan strategi pendekatan serta memberikan penyuluhan serta pelatihan kepada masyarakat perkotaan tentang metode hidroponik dengan media botol bekas. Rancangan awal yang direncanakan adalah melakukan analisis kebutuhan berdasarkan hasil praa survey sehingga dapat dijadikan sebagai kerangka acuan dalam pemenuhan kebutuhan masyarakat perkotaan sebagai upaya 
pemenuhan kebutuhan pangan. Langkah berikutnya adalah merancang kegiatan yang dilakukan berupa persiapan teknis yang dibutuhkan, pada fase ini merupakan sebuah bagian yang dianggap penting karena berkaitan dengan segala sesuatu yang diperlukan oleh masyarakat sasaran.

Tahap selanjutnya adalah mendatangkan narasumber mengenai kegiatan yang dilakukan dari fasilitator untuk memberikan menyuluhan kepada masyarakat tentang metode hidroponik menggunakan botol bekas. Dan pada tahap akhir akan dilakukan evaluasi sebagai upaya melihat sejauh mana kegiatan ini dapat berjalan dengan baik dan dapat memberikan solusi bagi bagi masyarakat perkotaan. Tahap kegiatan pelasanaan mengenai pendampingan dapat dilihat pada tabel 1 berikut ini:

\begin{tabular}{|l|l|c|c|c|c|}
\hline \multirow{2}{*}{ No. } & \multicolumn{1}{|c|}{ Kegiatan } & \multicolumn{4}{|c|}{ Bulan } \\
\cline { 3 - 6 } & \multicolumn{1}{|c|}{ Agustus } & September & Oktober & Nopember \\
\hline 1. & Praa survey & $\mathrm{v}$ & $\mathrm{v}$ & $\mathrm{v}$ & \\
\hline 2. & $\begin{array}{l}\text { Penggalian informasi } \\
\text { dan pengabdian }\end{array}$ & & $\mathrm{v}$ & $\mathrm{v}$ & \\
\hline 3. & Penulisan laporan & & & $\mathrm{v}$ & \\
\hline 4. & $\begin{array}{l}\text { Penyerahan laporan } \\
\text { akhir }\end{array}$ & & & & $\mathrm{V}$ \\
\hline
\end{tabular}

\section{HASIL DAN PEMBAHASAN}

Masyarakat daerah perkotaan di Kabupaten Tulungagung khususnya di Kecamatan Tulungagung mereka memiliki lahan yang tidak cukup besar sehingga mereka akan kesulitan dalam bercocok tanam. Salah satu metode yang dapat digunakan untuk bercocok tanaman dengan lahan yang sempit adalah dengan menggunakan metode hidroponik, namun masyarakat memiliki pemahaman bahwa metode hidroponik ememrlukan biaya yang cukup besar untuk membuatnya.

Perkembangan tehnologi saat ini mampu memberikan solusi bagi permasalahan yang dihadapi oleh masyarakat, diantaranya adalah masyarakat masih tetap bisa melakukan cocok tanam namun menggunakan metode hidroponik denagn biaya yang cukup ringan yaitu dengan menggunakan botol bekas.

Langkah-langkah yang dapat dilakukan pembuatan hidroponik dengan menggunakan media botol bekas adalah:

a. Menyiapkan botol bekas yang akan digunakan untuk media tanam kemudian dipotong menjadi dua bagian kemudian bagian ttup botol yang tealh dipotong diletakkan ke dalam bagian bawah botol dengan posisi tutup akan tampak terbalik

b. Menghubungakn kedua botol dengan menggunakan sumbu kompor, dan berfungsi seabagi penghubung nutrisi dengan media tanam.

c. Setelah semua rangkaian sudah terbentuk dan dapat berfungi dengan baik, dapat menuangkan zat ahra pada bagian bawah botol sebelum menyentuh tutup botol yang terbalik. Fungsinya adalah air yang memiliki nutrisi tinggi yang memiliki 
kandungan mineral tinggi yang diperlukan oleh tanaman untuk tanaman dapat melakukan fotosintesis.

d. Menyiapkan media tanam pada botol yang tebalik dengan mengisinya dengan bibit tanaman dan menggunakan media tanam berupa sekam bakar, rockwool ataupun cocopet.

e. Mengganti air secara berkala dengan tujuan dapat memenuhi kebutuhan zat hara yang berangsur-angsur berkurang.

Gambar 1. Metode Hydroponik

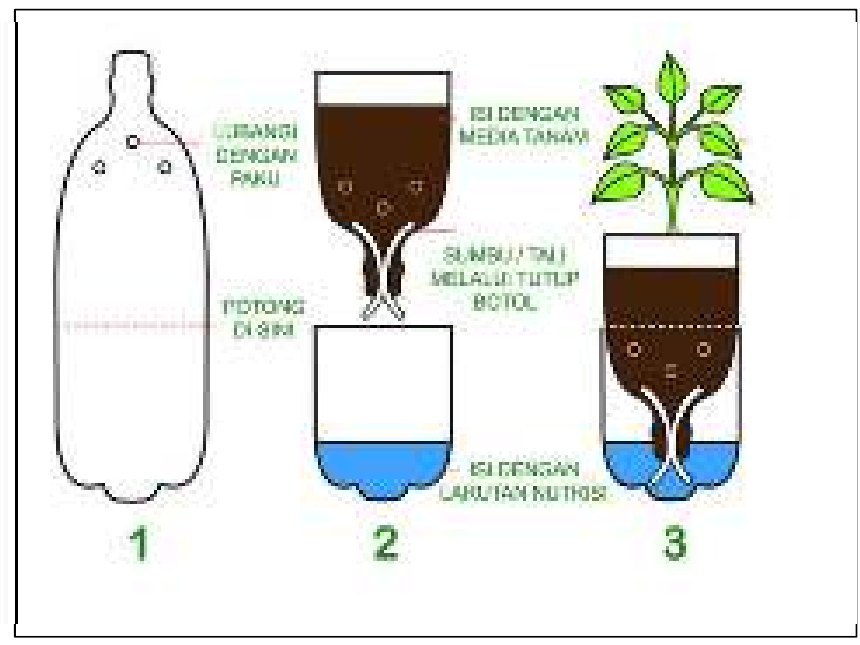

Gambar 2. Metode Hidroponic menggunakan botol bekas

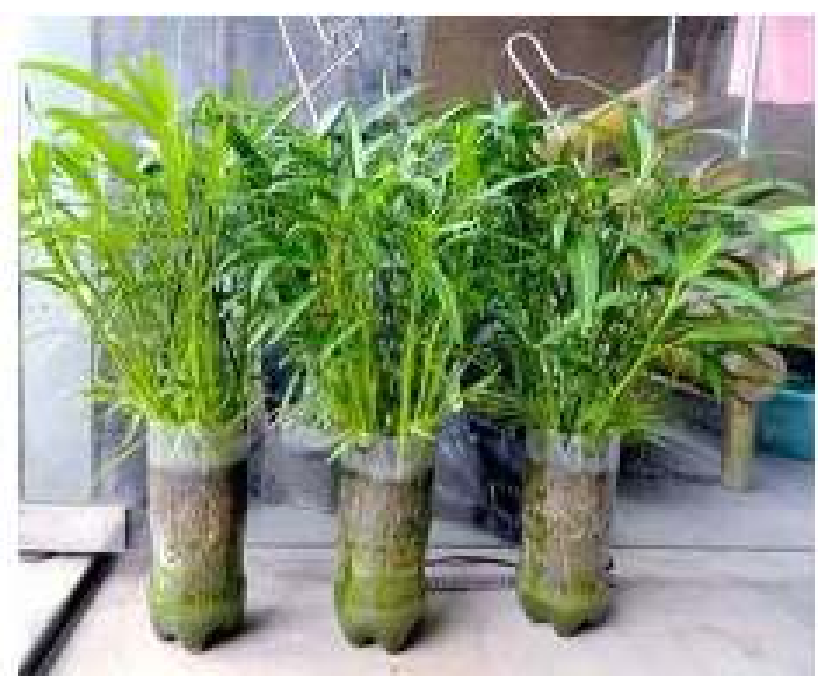


Gambar 3. Contoh bercocok tanam menggunakan media air

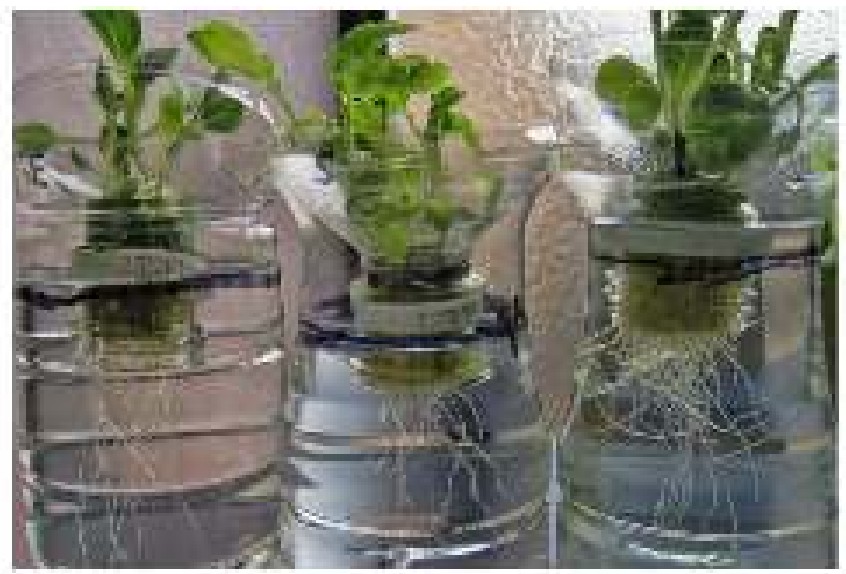

Poncmparall medis tanam mengㅛnakan ini harus memperhatikan jenis tanaman yang ditanam pada media ini, apakah tanaman tersebut memerlukan cahaya matahari yang cukup ataukah tidak. Cara yang dapat dilakukan untuk memaksimalkan hasil dapat dengan menambahkan pupuk kompos agar cepat panen. Metode hidropnik merupakan system bercocok tanam tanpa menggunakan media tanah didalamnya, media yang digunakan adalah botol bekas yang diisi dengan sir, sehingga untuk tanaman yang dapat ditanaman dengan menggunakan system ini adalah tanaman pada jenis tertentu seperti kangkung, sawi, selada. Pemilihan botol sebagai media tanam hidroponik karena botol bekas dirasa sangat mudah dicari disekeliling masyarakat, sehingga masyarakat perkotaan tidak perlu mencari media dengan harga yang cukup mahal.

Keuntungan dari bercocok tanam menggunakan metode hidroponik adalah:

a) Area bercocok tanam menjadi lebih bersih karena tidak menggunakan tanah sama sekali

b) Tingkat pertumbuhan tanaman dengan metode hidroponik lebih cepat, hal ini disebabkan karena nutrisi yang dibutuhkan oleh tanaman akan terserap secara lebih maksimal mengingat media yang berbentuk cair.

c) Meminimalisir penggunaan lahan yang luas

d) Lebih mudah melakukan kontrol pada tanaman akrena berada di pekarangan ataupun disekitar rumah

e) Resiko tanaman terserang hama serta penyakit akan lebih kecil

f) Bercocok tanam dengan metode ini sesuai pada kondisi cuaca panas maupun dingin.

g) Biaya yang dikeluarkan akan lebih murah

h) Dapat memberikan asupan gizi nabati yang cukup bagi keluarga

i) Menumbuhkan jiwa"gemar makan sayur" ddalam keluarga 
Dari keuntungan yang dapat diperoleh dari proses bercocok tanam dengan menggunakan metode hidroponik sehingga menjadi salah satu alternative solusi bagi masyarakat perkotaan yang ingin bercocok tanam, namun tidak memiliki lahan yang luas.

Kekurangan yang dimiliki oleh metode hidroponik adalah:

a) Memerlukan ketelitian ekstra utamanya harus mengontrol nutrisi yang diebrikan pada tumbuhan diantaranya adalahn tingkat keasaman $\mathrm{pH}$.

b) Memerlukan ketrampilan khusus di bidangnya dan dituntut memiliki kreativitas yang cukup tinggi.

c) Masyarakat masih enggan menggunakan metode ini karena merasa belum dapat diihat keuntungan pada skala yang lebih besar

Kelebihan dan kekurangan metode hidroponik ini harus dicermati supaya dapat menggunakan metode ini dengan benar sehingga dapat memberikan hasil yang masimal. Untuk itu perlu adanya kegaiatan yang dapat memberikan pemahaman masyarakat perkotaan menggunakan metode hidroponik ini merupakan metode yang tepat dan memberikan keuntungan yang cukup besar akan pemenuhan kebutuhan pangan khususnya pada skala rumah tangga.

Pemanfaatan pekarangan saat ini menjadi media yang cukup baik untuk menumbuhkan rasa bercocok tanam, akrena metode ini merupakan metode ayng revolusioner dan memberikan keuntungan yang cukup besar. Setelah masyarakat melakukan peneraman pola bercocok tanam dengan menggunakan metode hidroponik akan diperlukan evaluasi yang berkaiatan dengan keberhasilan dan keuntungan dari penerapan metode tersebut.

Saat ini keinginan masyarakat mengenai respon pada kesukaan anggota keluarga untuk mengkonsumsi makanan utamanya sayuran sangat rendah, untuk itu dengan mengajak masyarakat bercocok tanam dengan metode yang menyenangkan sehingga akan menimbulkan respon positif akan hal tersebut.

\section{PENUTUP}

\section{Simpulan}

Simpulan yang dapat diambil setelah melalui pendampingan terhdap masyarakat daerah perkotaan mengenai program pemenuhan kebutuhan pangan masyarakat dengan menggunakan metode hidroponik dengan botol sebaagi media sebagai berikut. Pertaman, masyarakat menjadi lebih memahami bahwa teradpat metode cocok tanam yang tidak memerlukan lahan yang luas dengan menggunakan metode hidroponik. Kedua, masyarakat mau bercocok tanam dipekrangan rumah sebagai pemenuhan kebutuhan pangan dengan skala rumah tangga dan menumbuhkan kebiasaan baru gemar makan sayur dalam keluarga. Kedua, indicator dari keberhasilan program ini adalah dengan jumlah rumah tangga yang bercocok tanam dengan menggunakan metode ini, masyrakat menerima dampak positif dari metode cocok tanam yang tengah mereka lakukan. Evaluasi yang dilakukan dalam kegiatan ini adalah dengan melihat dampak dari pengenalan metode hidroponik pasca mendapatkan pengenalan pada metode tersebut. 


\section{Saran Dan Rekomendasi}

Program pengabdian masyarakat mengenai pemenuhan kebutuhan pangan melalui hidroponik dengan media botol bekas di Kabupaten Tulungagung menghasilkan rekomendasi diantaranya adalah: (a) bagi masyarakat perkotaan dapat melakukan cocok tanam dengan metode hidroponik dengan menggunakan botol bekas (b) bagi pemerintah desa setempat dapat memebuat sebuah kelompok masyarakat di desanya masing-masing untuk dapat mengembangkan pola bercocok tanam tersebut sebagai upaya pemenuhan kebutahn pangan skala rumah tangga serta pemeanfaatan lahan pekarangan agar lebih produktif. Dari rekomendasi yang telah tersusun besar harapan supaya dapat menjadi pilot projeck untuk daerah-daerah lainnya di luar Kabupaten Tulungagung.

\section{E. DAFTAR PUSTAKA}

Anonim. 2010. Penggunaan Teknologi Fertigasi dalam Produksi Sayur-sayuran. Tersedia dari : URL: http://pertanianmjg.perak.gov.my/pdf/panduanfertilisasi.pdf[29 Juni 2010].

Chadirin,Y. 2001. Pelatihan Aplikasi Teknologi Hidroponik Untuk Pengembangan Agribisnis Perkotaan. Lembaga Penelitian Insitut Pertanian Bogor, Bogor.

Edi, S., dan J. Bbihoe. 2010. Budidaya Tanaman Sayuran. Balai Pengkajian Teknologi Pertanian, Jambi. 54 hal.

Hartus,T. 2002. Berkebun Hidroponik Secara Murah. Penebar Swadaya, Jakarta.

Haryanto, E., Tina S., dan Hendrosunarjono. 2003. Sawi dan Selada. Penebar Swadaya, Jakarta.

Karsono,S.,W.Sudarmodjo dan Y.Sutiyoso. 2002. Hidroponik Skala Rumah Tangga. Agromedia Pustaka, Jakarta.

Klaassen, G., M. Rory, Z. Justin, and N. Anderson. 2003. LED's: New Lighting Alternative for Greenhouse.

Lingga, P. 2005. Hidroponik Bercocok Tanam Tanpa Tanah. Penebar Swadaya, Jakarta.

Mas'ud, H. 2009. Sistem Hidroponik dengan Nutrisi dan Media Tanam Berbeda terhadap Pertumbuhan dan Hasil Selada. Media Litbang, Sulteng.

Poincelot, R.P. 1980. Horticulture: principles and practical applications. PrencticeHall, London.

Prihmantoro, H., dan Y.H. Indriani. 1999. Hidroponik Sayuran Semusim untuk Bisnis dan Hobi. Penebar Swadaya, Jakarta. 
Restiani, R. 2015. Pengaruh Jenis Almpu Terhadap Pertumbuhan dan Hasil Produksi Tanaman Selada (Lactuca sativa L) dalam Sistem Hidroponik Indoor [skripsi]. Lampung. Fakultas Pertanian, Universitas Lampung.

Rosliana, R dan N. Sumani. 2005. Budidaya Tanaman Sayuran dengan Teknik Hidroponik. Balai Penelitian Tanaman Sayuran Pusat Penelitian dan Pengembangan Hortikultura, Bandung. 27 Hal.

Sunarjono. 2003. Fisiologi Tanaman Budidaya. UI Press. Jakarta. 428 Hal.

Susila, A.D. 2013. Sistem Hidroponik. Departemen Agronomi dan Hortikultura. Fakultas Pertanian. Modul. IPB, Bogor. 20 Hal.

Wijayanto, Ari. 2015. Budidaya 10 Sayuran Paling Favorite. Araska publisher, Yogyakarta. 